\title{
Marine Environmental Emergencies in the North Pacific Ocean: Lessons Learned from Recent Oil Spills
}

\author{
Un Hyuk Yim ${ }^{1,2}$ (D) Jeffrey Short ${ }^{3}$
}

Received: 27 March 2017/ Accepted: 17 May 2017/Published online: 10 July 2017

(C) Springer Science+Business Media New York 2017

\begin{abstract}
Increasing marine vessel traffic, and oil and gas exploration and development throughout the North Pacific basin brings increasing risks of oil spills. Recognizing the serious challenges presented to response authorities, this Special Issue was organized by the North Pacific Marine Science Organization to provide an introduction to the current state of scientific understanding regarding the environmental effects of oil spills. Because interactions of spilled oils with biota and their habitats are complex, the most serious environmental damages from these spills are not necessarily those of greatest immediate concern by the public. Our overarching goal for this Special Issue is to provide an efficient introduction to the most important ways that oil spills can harm biota, habitats, and ecosystems through invited, targeted mini-reviews augmented by original research articles. We provide a brief background on the challenges posed by large oil spills to response authorities, summarize findings from the articles published in this Special Issue, and highlight some key research needs.
\end{abstract}

Un Hyuk Yim

uhyim@kiost.ac.kr

1 Oil and POPs Research Group, South Sea Research Institute, KIOST, Geoje 53201, Republic of Korea

2 Marine Environmental Science Major, Korea University of Science and Technology, Daejeon 34113, Republic of Korea

3 JWS Consulting LLC, Juneau, AK 99801, USA

\section{Background}

Increased globalization of markets has led to rapid growth in oil and gas exploration and development and maritime transport of fossil fuels and hazardous cargoes. This has increased the likelihood of coastal and ship-source incidents, presenting hazards to human health and often damaging marine ecosystems. Marine environmental emergency issues have become increasingly important for the nations around the North Pacific Ocean, but significant limitations in the capacity for governments to evaluate and monitor the short- and long-term ecological impacts of such emergencies continue to constrain responses.

Large scale, accidental releases of hazardous materials, including oil spills, chemical spills, and radionuclides, pose serious challenges for those charged with responding to marine environmental emergencies. Concurrent needs to mobilize response resources for containment, evaluate probable trajectories of discharges that escape containment, identify species and resources at risk of exposure and their pre-exposure abundance and contaminant burdens from confounding pollution sources, and implement environmental damage assessments must all be performed in a state of crisis, with limited time available for effective actions, rapidly changing conditions, and considerable uncertainty. Large oils spills can overwhelm even the best prepared response agencies supported by the wealthiest governments, as evidenced by the 2010 Deepwater Horizon blowout in the Gulf of Mexico (DWH Trustees 2015).

With any spill, the validity of environmental damage assessments may depend on the willingness of response authorities to support these efforts, which requires balancing the value of accurate damage assessments against the immediate needs of response activities directed toward mitigation, especially during the initial phases of an oil 
spill. Strong short-term incentives to focus resources on mitigation and restoration may lead response authorities to neglect environmental damage assessments, and consequently damage pathways may remain undiscovered because inadequate efforts are made to evaluate them. In the long term, this may delay or preclude a recognition of which natural resources would benefit most from restoration efforts.

Because every oil spill involves a unique combination of circumstances, each requires response and damage assessment efforts adapted to the circumstances. This must occur quickly and carefully to anticipate accurately the kinds and locations of effects most likely to occur. Those conducting environmental damage assessments should be alert to the possibility of previously unrecognized, adverse effects. Large oil spills cause abrupt perturbations of marine ecosystems, and the responses of those ecosystems may provide clues about how oil contamination alters ecosystem functions (Underwood 1996, Short et al. 2017). Careful studies of oil spills during the past 30 years have resulted in several discoveries about how oil spills may affect marine ecosystems, and it is possible that other major damage pathways remain to be discovered.

This Special Issue presents new findings related to major oil spills in the North Pacific Ocean region, augmented by findings from the 2010 Deepwater Horizon blowout, the most recent intensively studied major marine oil discharge. The collection of manuscripts draws on presentations made at an expert meeting hosted by the North Pacific Marine Science Organization in Qingdao, China in October 2015. The goals of the meeting were (1) to summarize important examples of North Pacific marine environmental emergencies, (2) to develop environmental response and monitoring strategies for the North Pacific Ocean in light of environmental emergencies, and (3) to improve responsiveness and effectiveness of current national approaches to manage and mitigate such emergencies in the North Pacific region. Accordingly, this Special Issue addresses oil spills, their impacts on the marine environment, and detection and monitoring methods for oil spills.

Thankfully, major oil spills are rare, but because of this, institutional memory of prior oil spills is preserved with difficulty. The typical crisis atmosphere immediately following a spill limits the time available to responders to orchestrate concurrent mitigation and damage assessment effort. When this takes place with limited scientific guidance, decisions may lead to inappropriate efforts. We hope that the papers in this volume will help response authorities to formulate scientifically informed policies that balance immediate needs for mitigation and efforts needed to preserve the integrity of natural resource damage assessments, especially in jurisdictions with little past experience with oil spills.

\section{Papers Presented in this Special Issue}

The contributed papers include six mini-reviews of oil spill effects, six case studies presenting results of original research on oil spills, and two methodological studies.

\section{Mini-reviews}

Short (2017) reviews the substantive discoveries of new environmental effects of oil spills beginning with the Exxon Valdez through the Deepwater Horizon, noting that additional mechanisms leading to environmental damage almost certainly remain to be discovered. Hodson (2017) reviews the effects of polycyclic aromatic hydrocarbon (PAH) structure on toxicity to fish embryos, the most sensitive life stage, and Incardona (2017) reviews the molecular biological pathways through which this toxicity acts. Haney et al. (2017) review the challenges associated with assessing the effects of oil spills on birds in the deep ocean, where collection of oiled carcasses or other evidence of oil exposure is often not practical. Barron (2017) reviews the status of research on photoenhanced toxicity of petroleum to aquatic invertebrates and fish, which is increasingly recognized as an important environmental damage pathway for organisms that inhabit surface waters exposed to ultraviolet radiation and have translucent tissues. Finally, Yim et al. (2017) and Spies et al. (2017) review the environmental effects of the 2007 Hebei Spirit oil spill in Korea and 2009 Montara oil well blowout in the Coral Sea, respectively, illustrating how a prompt and thorough damage assessment (Hebei Spirit) contrasts with one that is delayed and minimal (Montara).

\section{Case Studies}

Dubansky et al. (2017) present new evidence of how fish were exposed to different crude oil components in the field following the 2010 Deepwater Horizon oil well blowout. Short et al. (2017) present evidence for a strong indirect effect of this blowout indicated by unprecedented recruitment of forage fish that were released from predation after seabirds that prey on them were killed in large numbers. Kim et al. (2017) summarize long-term monitoring results of the 2007 Hebei Spirit oil spill in Korea. Loh et al. (2017) present monitoring results for PAHs in bivalves following the $W u Y i$ San oil spill in Korea, along with a human health risk assessment for consumption of these bivalves. Finally, Morales-Caselles et al. (2017) show how individual alkyl-substituted PAH homologues allow discrimination of oil released by the 2015 Marathassa oil spill in Vancouver, Canada from nearby confounding PAH sources. 


\section{Methodological Studies}

Rosenberger et al. (2017) present a conceptual framework for evaluating risks posed by oil spills to marine mammals in British Columbia waters, which may be readily generalized to other jurisdictions. Li et al. (2017) present performance results for a new approach for remotely-sensing oil spills on the sea surface by satellite and monitoring their size and movements, which may substantially aid oil spill response and damage assessment efforts.

\section{Research Gaps}

Recognizing the complexity of interactions between oil and the environment, contributors to this Special Issue noted research efforts are needed to determine the effects of unrecognized toxic compounds from oil, standardization of toxicity testing exposure protocols, long-term effects following short-term exposures, indirect ecological effects, and improvements to emergency field investigation strategies and monitoring methods. Our understanding of toxicity mechanisms at the molecular level and the specific compounds in petroleum that trigger these mechanisms is clearly incomplete, and it is very likely that toxicity mechanisms and presently unidentified compounds that act through known and unknown pathways remain to be discovered. Greater use of effects-driven assays will likely facilitate discovery of the toxic effects of aliphatics, other oil constituents, and oxidation, and other degradation products from weathering processes.

At present, generation of water accommodated fraction (WAF) from oil is the only standardized protocol for exposure testing. Various other oiling simulations, such as oiled gravels and sands, also need standardization. There exist no widely accepted protocols for UV exposure conditions, despite numerous studies demonstrating photoenhanced toxicity. Other routes of exposure need to be considered, such as oiled suspended particulate matter aggregates (OSA) in turbid environments and the effects of oil ingested by fish and other biota.

Short-term exposures to oil may cause long-term effects, as clearly demonstrated by Heintz et al. (2000) for pink salmon (Oncorhynchus gorbuscha). The long-term effects following short-term exposures of pink salmon and other biota to oil, to specific oil constituents, or to oil degradation products from weathering processes remain largely unexplored and may lead to other discoveries, such as the marine survival impacts observed by Heintz et al. (2000). Moreover, at the broader ecosystem level, indirect effects of large oil spills may reverberate through strong trophic or other ecological linkages and the study of these effects is in its infancy.
Finally, emergency field investigation strategies and monitoring methods need improvements. The assessments of oil discharge volumes and the extent of oiling in seawater, sediment, biota and the atmosphere as soon as possible after the spill are the crucial first step of environmental impact assessments or natural resource damage assessments. Most emergency monitoring techniques, such as shoreline cleanup assessment techniques (i.e., SCAT), are designed to support oil spill cleanup. Augmenting SCAT efforts with more quantitative assessments of shoreline oiling are needed to provide a basis for evaluating oil persistence for more accurate assessments of habitat damage. Currently available field monitoring tools are mostly based on infrared and fluorescence spectrophotometry due to their ease of use in the field, and improvements in these and related support methods would facilitate monitoring. Establishing pre-spill protocols for identifying and sampling habitats and organisms at risk of oiling before their actual contamination, and maintaining agency resources and personnel equipped to execute these protocols, is probably the single greatest improvement that spill response authorities could adopt to better recognize and measure the effects of a spill. These protocols could provide initial acute exposure information that might otherwise be underestimated after the emergency cleanup at sea or on shore. For example, Loh et al. (2017) showed that accumulation and depuration of PAHs in oysters corresponded with field cleanup activities, implying initial exposure concentrations could be relatively higher than would otherwise have been reported.

Acknowledgements The authors acknowledge the North Pacific Marine Science Organization (PICES), the International Council for the Exploration of the Sea (ICES), and the Northwest Pacific Action Plan (NOWPAP) for their support of the workshop on "Marine environmental emergencies: Detection, monitoring, response and impacts" held in Qingdao (China) in October 2015. One outcome of this workshop was a call for this Special Issue. Dr. Un Hyuk Yim's work was partly supported by the project entitled "Oil Spill Environmental Impact Assessment and Environmental Restoration" funded by the Ministry of Oceans and Fisheries of Korea.

\section{References}

Barron MG (2017) Photoenhanced toxicity of petroleum to aquatic invertebrates and fish. Arch Environ Contam Toxicol. doi:10. 1007/s00244-016-0360-y

Dubansky B, Rice CD, Galvez F (2017) Biomarkers of arylhydrocarbon receptor activity in Gulf killifish (Fundulus grandis) from the northern Gulf of Mexico marshes following the Deepwater Horizon Oil Spill. Arch Environ Contam Toxicol. doi:10.1007/s00244-017-0417-6

DWH Trustees (Deepwater Horizon Natural Resource Damage Assessment Trustees) (2015) Deepwater horizon oil spill: draft programmatic damage assessment and restoration plan and draft programmatic environmental impact statement. Chapter 1, sec. 
1.5.1. http://www.gulfspillrestoration.noaa.gov/sites/default/files/ wp-content/uploads/Front-Matter-and-Chapter-1_Introductionand-Executive-Summary_508.pdf

Haney JC, Jodice PGR, Montevecchi WA, Evers DC (2017) Challenges to oil spill assessment for seabirds in the deep ocean. Arch Environ Contam Toxicol. doi:10.1007/s00244-0160355-8

Heintz RA, Rice SD, Wertheimer AC, Bradshaw RF, Thrower FP, Joyce JE, Short JW (2000) Delayed effects on growth and marine survival of pink salmon Oncorhynchus gorbuscha after exposure to crude oil during embryonic development. Mar Ecol Prog Ser 208:205-216

Hodson PV (2017) The toxicity to fish embryos of PAH in crude and refined oils. Arch Environ Contam Toxicol. doi:10.1007/s00244016-0357-6

Incardona JP (2017) Molecular mechanisms of crude oil developmental toxicity in fish. Arch Environ Contam Toxicol. doi:10. 1007/s00244-017-0381-1

Kim M, Jung JH, Ha SY, An JG, Shim WJ, Yim UH (2017) Longterm monitoring of PAH contamination in sediment and recovery after the Hebei Spirit oil spill. Arch Environ Contam Toxicol. doi:10.1007/s00244-017-0365-1

Li Y, Cui C, Liu Z, Liu B, Xu J, Zhu X, Hou Y (2017) Detection and monitoring of oil spills using moderate/high-resolution remote sensing images. Arch Environ Contam Toxicol. doi:10.1007/ s00244-016-0358-5

Loh A, Yim UH, Ha SY, An JG, Kim M (2017) Contamination and human health risk assessment of polycyclic aromatic hydrocarbons (PAHs) in oysters after the Wu Yi San oil spill in Korea. Arch Environ Contam Toxicol. doi:10.1007/s00244-017-0394-9
Morales-Caselles C, Yunker M, Ross PS (2017) Identification of spilled oil from the MV Marathassa (Vancouver, Canada 2015) using alkyl PAH isomer ratios. Arch Environ Contam Toxicol. doi:10.1007/s00244-017-0390-0

Rosenberger ALJ, MacDuffee M, Rosenberger AGJ, Ross PS (2017) Oil spills and marine mammals in British Columbia, Canada: development and application of a risk-based conceptual framework. Arch Environ Contam Toxicol. doi:10.1007/s00244-0170408-7

Short JW (2017) Advances in understanding the fate and effects of oil from accidental spills in the United States beginning with the Exxon Valdez. Arch Environ Contam Toxicol. doi:10.1007/ s00244-016-0359-4

Short JW, Geiger HJ, Haney JC, Voss CM, Vozzo ML, Guillory V, Peterson CH (2017) Anomalously high recruitment of the 2010 Gulf menhaden (Brevoortia patronus) year class: evidence of indirect effects from the Deepwater Horizon blowout in the Gulf of Mexico. Arch Environ Contam Toxicol. doi:10.1007/s00244017-0374-0

Spies RB, Mukhtasor M, Burns KA (2017) The montara oil spill: a 2009 well blowout in the Timor Sea. Arch Environ Contam Toxicol. doi:10.1007/s00244-016-0356-7

Underwood AJ (1996) Detection, interpretation, prediction and management of environmental disturbances: some roles for experimental marine ecology. J Exp Mar Biol Ecol 200:1-27

Yim UH, Khim JS, Kim M, Jung JH, Shim WJ (2017) Environmental impacts and recovery after the Hebei Spirit oil spill in Korea. Arch Environ Contam Toxicol. doi:10.1007/s00244-017-0375-Z 